\title{
Flavonoids as a potential adjuvant therapy of COVID-19?
}

\author{
Torkos $\mathrm{T}^{1}$, Macay $\mathrm{J}^{2}$ \\ 8 Benfield, Grasmere, Cumbria, LA22 9RD, United Kingdom. mejcej@gmail.com
}

Text in PDF www.elis.sk.

\section{Dear Editor in-Chief,}

We are writing to you with reference to the current global efforts aimed at finding a truly efficient treatment of coronavirus disease 2019 (COVID-19), and to a recent paper by Professor Hatala R (1) published in AEPress (electronic version) wherein he deems the high prevalence of mostly subclinical infections of health care workers a crucial factor influencing the transmission of the disease to elderly polymorbid persons. Consequently, we would like to bring to your attention the potential of a supportive treatment, in particular a treatment that will in no case aggravate the situation for this highly vulnerable segment of the population whilst also having the potential to be applied as a preventive measure to all persons, including health care professionals.

The suggestions of Professor Hatala concerning the treatment are truly overwhelming. The idea of protection of the human body through interventions in the immune system, whilst having its merit, is not necessarily acceptable to everyone. Here we would like to refer to a paper published in JAMA (2), wherein the authors also deal with the potential of adjunctive therapies. We are trying to point out the idea that protection against the infection through application of natural substances that are harmless by their nature carries no restrictions; on the contrary, it can be compared with ingestion of vitamins in their natural form, such as consumption of fruits. Substances contained in natural sources, when processed by means of nanotechnologies, contribute to their better biological availability, and hence high efficacy. One of such groups of substances are repesented by flavonoids which, according to Lei Zhang and Yunhui Liu (3), exhibit coronavirus protease-inhibiting activity.

According to Ginter and Simko ${ }^{4}$, polyphenolic compounds with their largest group of flavonoids, apart from having the ability to downregulate expression of proinflammatory mediators in heart disease, possess also an antithrombotic effect, that can be used in microthrombotic events described by Bilaloglu ${ }^{5}$ et al in JAMA in $16 \%$ of patients hospitalized with COVID-19.

\section{References}

1. Hatala R. Proposal for complementary targeted public health antiepidemic measures during the pandemics of COVID-19.

2. Sanders JM, Monogue ML, Jodlowski TZ, Cutrell JB. Pharmacologic Treatments for Coronavirus Disease 2019 (COVID-19): A Review. JAMA.

3. Lei Zhang, Yunhui Liu. Potential interventions for novel coronavirus in China: A systematic review. J Med Virol 2020; 92:479-490.

4. Ginter E, Simko V. Plant polyphenols in prevention of heart disease. Bratisl Lek Listy 2012; 476-480.

5. Seda Bilaloglu, Yin Aphinyanaphongs, Simon Jones et al. Thrombosis in Hospitalized Patients with COVID-19 in a New York City Health System. JAMA
${ }^{1}$ Highly Specialized Professional Institute of Geriatrics, St. Lukas, Stroja-
renska 13, 04001 Kosice, Slovakia and ${ }^{2}$ Benfield 8, Grasmere, Cumbria,
LA22 9RD, United Kingdom

Address for correspondence: J. Macaj, 3 Market Strand, Padstow, Cornwall, PL28 8AH, United Kingdom
Received May 15, 2020. Accepted June 10, 2020. 